\title{
The Human Cathelicidin LL-37 Host Defense Peptide Upregulates Tight Junction-Related Proteins and Increases Human Epidermal Keratinocyte Barrier Function
}

\author{
Toshihiro Akiyama ${ }^{a, b}$ François Niyonsaba ${ }^{b}$ Chanisa Kiatsurayanon ${ }^{a, b}$ \\ Toan The Nguyen $^{a, b}$ Hiroko Ushio ${ }^{b}$ Tsutomu Fujimura ${ }^{c}$ Takashi Ueno ${ }^{c}$ \\ Ko Okumura ${ }^{b}$ Hideoki Ogawab Shigaku Ikeda $^{\mathrm{a}, \mathrm{b}}$ \\ a Department of Dermatology, ${ }^{\mathrm{b}}$ Atopy (Allergy) Research Center and 'Division of Biomedical Research Center, \\ Juntendo University Graduate School of Medicine, Tokyo, Japan
}

\section{Key Words}

Antimicrobial peptide $\cdot$ Cathelicidin LL-37 · Keratinocyte $\cdot$

Skin barrier - Tight junction

\begin{abstract}
Both psoriasis and atopic dermatitis (AD) are not only associated with an impaired stratum corneum barrier, but also with abnormal expression of the tight junction (TJ) proteins. Because host defense peptides, including LL-37, are overexpressed in lesional psoriatic skin but are downregulated in lesional AD skin, we hypothesized that LL-37 might regulate the TJ function in keratinocytes. We demonstrated that LL37 selectively increased the expression of several claudins and occludin, and enhanced their membrane distribution. Furthermore, LL-37 elevated the transepithelial electrical resistance while reducing the paracellular permeability of keratinocyte layers, and this activity was weakened by the claudin inhibitor ochratoxin A. A characterization of the molecular mechanism underlying the regulation of the TJ barrier by LL-37 revealed that LL-37 induced the activation of the Rac1, atypical PKC, glycogen synthase kinase-3 and PI3K pathways, and the specific inhibition of these pathways reversed
\end{abstract}

the LL-37-mediated regulation of TJ function. In addition, LL37 enhanced the expression of differentiation markers under the control of ochratoxin A, suggesting an association between LL-37-induced TJ function and keratinocyte differentiation. These data provide novel evidence that, in addition to its antimicrobial and other immunoregulatory functions, LL-37 contributes to cutaneous immunity by strengthening the skin's barrier function.

(c) 2014 S. Karger AG, Basel

\section{Introduction}

Host defense peptides (HDPs), also known as antimicrobial peptides, are commonly cationic and form a variety of structural motifs that are generally 10-50 aa in length and contain up to $50 \%$ hydrophobic amino acids. According to the antimicrobial peptide database (http:// aps.unmc.edu/AP/main.php), more than 2,000 HDPs have been discovered to date. Initially, HDPs were identified as endogenous antibiotics due to their ability to kill various pathogens. However, recent studies have demonstrated that these peptides are implicated in diverse bio-

\section{KARGER}

\section{(c) 2014 S. Karger AG, Basel}

$1662-811 X / 14 / 0066-0739 \$ 39.50 / 0$

E-Mail karger@karger.com

www.karger.com/jin
Dr. François Niyonsaba

Atopy (Allergy) Research Center, Juntendo University Graduate School of Medicine

2-1-1 Hongo, Bunkyo-ku

Tokyo 113-8421 (Japan)

E-Mail francois@juntendo.ac.jp 
logical processes, such as promoting chemotaxis, stimulating the production of cytokines and chemokines, modulating dendritic cell and macrophage differentiation, regulating neutrophil and epithelial cell apoptosis, suppressing pro-inflammatory responses, inducing angiogenesis and inducing wound healing [reviewed in 1]. To date, several hundred HDPs have been identified in human skin, where they are expressed constitutively or are induced in dangerous situations such as skin injury or infection. Among the skin-derived HDPs, cathelicidin LL-37, human $\beta$-defensins (hBDs) and the S100 protein psoriasin (S100A7) have been shown to play key roles in cutaneous defense [1].

Cathelicidins consist of a highly conserved N-terminal cathelin domain and a mature, active, variable $\mathrm{C}$-terminal peptide that is proteolytically released upon activation [2]. The single human member of the cathelicidin family is the $18-\mathrm{kDa}$ human cationic antibacterial protein (hCAP18), and the mature peptide derived from hCAP18 is termed LL-37. In skin, LL-37 is synthesized by keratinocytes and by neutrophils that transport LL-37 when they infiltrate infected or wounded skin [1]. In healthy skin, LL-37 expression is barely detectable in keratinocytes; however, during infection or injury, LL-37 production by these cells is strongly increased [3]. In addition to this peptide's antimicrobial activity, we and others have previously demonstrated that LL-37 has a broad spectrum of immunomodulatory properties in epithelial cells and keratinocytes, including the stimulation of cytokine/ chemokine secretion, the induction of migration and proliferation, the modulation of cell survival, and the promotion of wound healing [1]. The in vivo importance of LL-37 and other cathelicidins in the prevention of skin infections has been demonstrated in experimental studies. For instance, mice that do not express cathelin-related antimicrobial peptide, or CRAMP, an LL-37 ortholog, exhibit increased susceptibility to group A Streptococcus infections [4].

HDPs, including LL-37, hBDs and psoriasin, have been implicated in the pathologies of inflammatory and autoimmune skin diseases such as psoriasis and atopic dermatitis (AD) [1], and the presence of large numbers of these HDPs in lesional psoriatic skin helps explain why patients with psoriasis experience fewer cutaneous infections than expected [5]. It has been reported that, compared with lesional psoriatic skin, the lesional $\mathrm{AD}$ skin displays an impaired induction of HDPs such as hBDs and LL-37 [6], which explains the frequent bacterial infections in $\mathrm{AD}$ patients. However, it appears that the induction of HDPs is not generally impaired in lesional AD skin, as shown by a recent study showing enhanced expression of hBD-2, hBD-3, psoriasin and ribonuclease 7 in the lesional skin of AD patients compared with nonlesional skin and healthy controls, although the absolute levels of HDP secretion were lower than the levels detected in psoriasis patients [7]. Although both psoriatic and AD skin have been associated with stratum corneum barrier defects, a recent report showed that, in contrast to uninvolved psoriasis, uninvolved $\mathrm{AD}$ skin displays a reduced expression of tight junction (TJ) proteins, which causes the barrier dysfunction observed in $\mathrm{AD}$ patients [8].

TJs serve as a physical barrier to prevent solutes and water from passing through the paracellular space. TJs create this barrier by forming cell-cell junctions that connect neighboring cells, control the paracellular passage of molecules (barrier function), and separate the apical and the basolateral portions of the cell membrane (fence function) [9]. In addition, TJs play important roles in cell differentiation and proliferation, cell communication and cell polarity [10]. In the human epidermis, TJs are composed of transmembrane proteins such as claudins, occludin and junctional adhesion molecules, which are clustered and stabilized by cytosolic plaque proteins called zonula occludens [11]. Claudins play an essential role in the regulation of $\mathrm{TJ}$ function by tightening or disrupting the epithelial barrier $[12,13]$. HDPs such as hBDs and LL-37 are reduced in lesional AD skin but overexpressed in lesional psoriatic skin [6], and the expression of $\mathrm{TJ}$ proteins is impaired in uninvolved $\mathrm{AD}$ skin but normal, decreased or increased in psoriatic skin [14-16]. Therefore, we hypothesized that, beyond their dual roles as antimicrobial agents and immunomodulators, HDPs may perform additional functions in the regulation of $\mathrm{cu}-$ taneous barrier function.

In this study, we showed that LL-37 markedly enhances the expression and membrane distribution of various TJ proteins, including claudins and occludin, and contributes to the regulation of $\mathrm{TJ}$ barrier function by increasing the transepithelial electrical resistance (TER) and reducing the paracellular flux in keratinocyte layers. The LL-37-mediated regulation of TJ barrier function involved various pathways, such as the atypical protein kinase C (aPKC), Rac1, glycogen synthase kinase (GSK)-3 and PI3K pathways. Furthermore, LL-37 induced the expression of several keratinocyte differentiation-specific proteins; this upregulated expression was reduced by the presence of ochratoxin A. These data demonstrate that LL-37 displays a novel role in cutaneous innate immunity by regulating $\mathrm{TJ}$ barrier function. 


\section{Materials and Methods}

\section{Reagents}

LL-37 (L ${ }^{1}$ LGDFFRKSKEKIGKEFKRIVQRIKDFLRNLVPRT$\mathrm{ES}^{37}$ ) was synthesized using the solid-phase method with a peptide synthesizer (Model PSSM-8; Shimadzu, Kyoto, Japan) by fluorenylmethoxycarbonyl chemistry, and the molecular mass was confirmed with a mass spectrometer (Model TSQ 700; Thermo Quest Finnigan, Manchester, UK). The filaggrin antibody was obtained from Abcam (Tokyo, Japan), the involucrin antibody was from Santa Cruz Biotechnology (Santa Cruz, Calif., USA), and the keratin 1, keratin 10 and transglutaminase 1 antibodies were purchased from Novus Biologicals (Littleton, Colo., USA). The anti-claudin-1, 3, 4 and 7 and occludin antibodies were purchased from Invitrogen (Carlsbad, Calif., USA), and the anti-claudin- 9 and 14 antibodies were obtained from Abcam. The anti-phosphorylated GSK-3 $\alpha / \beta$ (Tyr279/Tyr216), PKC $\zeta / \lambda$ and PI3K antibodies, as well as the GSK-3 $\alpha / \beta, \mathrm{PKC} \zeta$ and PI3K antibodies, were purchased from Cell Signaling Technology (Beverly, Mass., USA). GF109203X was purchased from Enzo Life Sciences (Farmingdale, N.Y., USA), SB 415286 was obtained from Tocris Bioscience (Bristol, UK), and wortmannin and ochratoxin A were purchased from Sigma-Aldrich (St. Louis, Mo., USA). NSC23766 was obtained from Calbiochem (La Jolla, Calif., USA).

\section{Keratinocyte Culture and Stimulation}

Primary human epidermal keratinocytes isolated from neonatal foreskins were purchased from Kurabo Industries (Osaka, Japan) and were cultured in serum-free HuMedia-KG2 keratinocyte growth medium (Kurabo Industries), as previously described [17]. The cells were serially passaged at $60-70 \%$ confluence, and the experiments were conducted at passage three using subconfluent cells (60-80\% confluence) in the proliferative phase, unless otherwise specified. For total RNA extraction and Western blot analysis, keratinocytes were cultured in 12-well tissue culture plates, washed with PBS and incubated with LL-37 in HuMedia without supplements for the indicated periods. For the TER and paracellular flux assays, $0.72 \times 10^{5}$ cells were plated onto transwells of $0.4-\mu \mathrm{m}$ pore size (Millipore, Billerica, Mass., USA) and were switched to high$\mathrm{Ca}^{2+}(1.35 \mathrm{mM})$ medium after reaching confluence.

\section{Total RNA Extraction and Real-Time Quantitative PCR}

Total RNA was extracted from keratinocytes using the RNeasy Plus Micro kit (Qiagen, Hilden, Germany), and first-strand cDNA was synthesized from $1 \mu \mathrm{g}$ of total RNA using the ReverTra Ace qPCR RT kit (Toyobo, Osaka, Japan), according to the manufacturer's instructions. Real-time PCR was performed using the TaqMan Universal PCR Master Mix (Applied Biosystems, Branchburg, N.J., USA). Amplification and detection of mRNA were performed using the StepOnePlus Real-Time PCR System (Applied Biosystems) following the manufacturer's specifications. All the primer/ probe sets used in this study were obtained from Applied Biosystems' Assays-on-Demand; the order numbers are listed in online supplementary table S1 (for all online suppl. material, see www. karger.com/doi/10.1159/000362789). All the real-time PCR reactions were performed in triplicate, and the changes in gene expression are reported as fold increases relative to untreated controls.

Western Blot Analysis

Keratinocytes cultured in high-Ca ${ }^{2+}$ medium were incubated with LL-37 for the indicated time periods. After stimulation, ly- sates were obtained by lysing the cells in RIPA buffer (Cell Signaling Technology). The total protein concentrations were determined using the Precision Red Advanced Protein Assay kit (Cytoskeleton, Denver, Colo., USA), and equal amounts of total protein were subjected to $12.5 \%$ SDS-PAGE. Non-specific binding sites were blocked with Immunoblock (Dainippon-Pharm, Osaka, Japan) for $1 \mathrm{~h}$ at room temperature. The blots were incubated overnight according to the manufacturer's instructions, with the appropriate antibodies diluted in a mixture of TBS containing $0.1 \%$ Tween 20 and Immunoblock (1:1). The antibodies and the conditions of their use are outlined in online supplementary table S2. The membrane was developed with the Luminata Forte Western HRP substrate (Millipore, Billerica, Mass., USA) and was imaged using Fujifilm LAS-4000 Plus (Fujifilm, Tokyo, Japan). To quantify the band intensities, a densitometry analysis was performed using the software program Image Gauge (LAS-4000 Plus, Fujifilm) to correct for protein loading discrepancies. In some of the experiments, the cells in high- $\mathrm{Ca}^{2+}$ medium were pretreated with ochratoxin A, NSC23766, GF109203X, SB 415286 or wortmannin, and Western blotting was performed as above.

\section{Measurements of TER and Paracellular Flux}

Keratinocytes grown on $0.6-\mathrm{cm}^{2}$ transwell filters were transferred into high-Ca ${ }^{2+}$ medium, and LL-37 was added to both the apical and basal compartments. The TER across the keratinocyte layers was measured at $0-120 \mathrm{~h}$ after culture using cellZscope (nanoAnalytics, Münster, Germany). The TER values were corrected by subtracting the value of a blank (no cells) and were expressed in $\Omega \cdot \mathrm{cm}^{2}$. Keratinocytes were also grown on $0.3-\mathrm{cm}^{2}$ transwell filters, and the paracellular flux assay was performed as previously described using 4-kDa FITC-dextran (Sigma-Aldrich) as a tracer [18]. Briefly, after the chambers were transferred into high- $\mathrm{Ca}^{2+}$ medium, the keratinocyte layers were stimulated with LL-37 for $0-120 \mathrm{~h}$. The media in the apical and basal compartments were replaced with $250 \mu \mathrm{l}$ of P buffer (10 mM HEPES, $\mathrm{pH} 7.4,1 \mathrm{~mm}$ sodium pyruvate, $10 \mathrm{~mm}$ glucose, $3 \mathrm{mM} \mathrm{CaCl}_{2}$ and $145 \mathrm{~mm} \mathrm{NaCl}$ ) containing $10 \mathrm{mg} / \mathrm{ml}$ FITC-dextran and $700 \mu \mathrm{l}$ of $\mathrm{P}$ buffer, respectively. After $2 \mathrm{~h}$, the medium was collected from the basal compartment and the fluorescence was measured with a fluorimeter (Nihon Molecular Devices, Tokyo, Japan).

In some experiments, chambers were transferred into high$\mathrm{Ca}^{2+}$ medium, and keratinocyte layers were treated with various inhibitors before the addition of LL-37. TER and paracellular flux were then measured at $96 \mathrm{~h}$. The doses of inhibitors used in this study were not toxic to the keratinocytes, as confirmed by lactate dehydrogenase activity assay (data not shown). All the experiments included DMSO vehicle controls, and the levels of DMSO in the cell cultures never exceeded $0.1 \%$ (data not shown).

\section{Rac1 Activation Assay}

In accordance with the manufacturer's protocol (Cytoskeleton), keratinocytes at about $50 \%$ confluence were stimulated with LL-37 for 0-96 h. Following stimulation, lysates were obtained by lysing the cells in RIPA buffer supplemented with a protease inhibitor cocktail, and the total protein concentrations were determined using the Precision Red Advanced Protein Assay kit (Cytoskeleton). Rac1 activation was determined using the Rac1 activation assay kit (Cytoskeleton) according to the manufacturer's recommendations. 


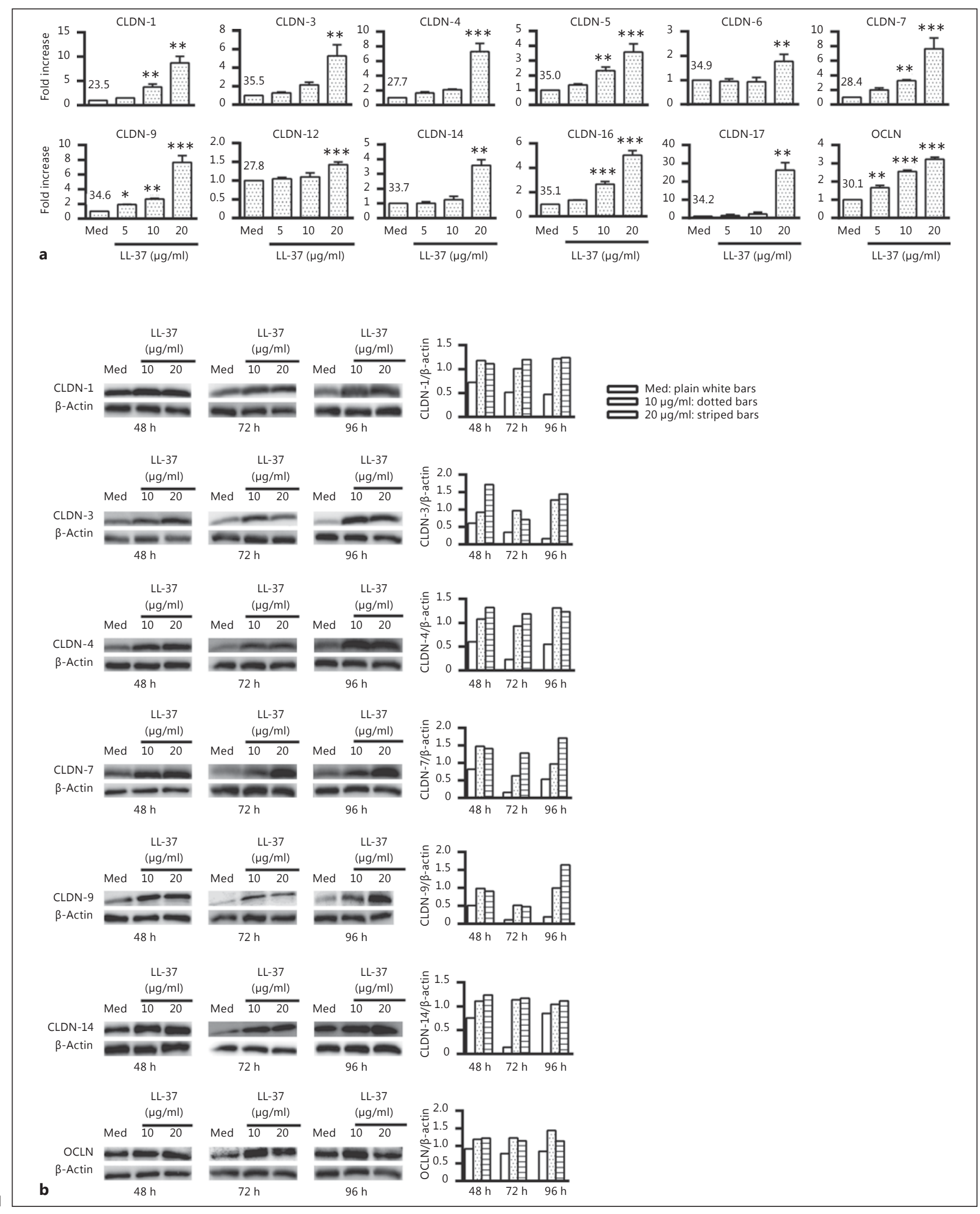

(For legend see next page.) 
Immunofluorescence Microscopy

Keratinocytes were cultured in high- $\mathrm{Ca}^{2+}$ medium on collagen I-coated chamber slides (BD Biosciences, Bedford, Mass., USA) and were stimulated with LL-37 for $96 \mathrm{~h}$. Following fixation with methanol for $15 \mathrm{~min}$ at $4^{\circ} \mathrm{C}$, the cells were blocked in Protein Block Serum-Free (DakoCytomation, Carpinteria, Calif., USA) containing $0.2 \%$ Tween-20 for $20 \mathrm{~min}$ at room temperature. The cells were then incubated overnight at $4{ }^{\circ} \mathrm{C}$ with the appropriate primary antibodies diluted in $1 \%$ BSA (BSA-PBS) containing $0.1 \%$ Tween 20 , followed by incubation with specific secondary antibodies coupled to Alexa 594 (Invitrogen) for $30 \mathrm{~min}$ at room temperature. Images were captured using confocal laser scanning microscopy (Carl Zeiss, Jena, Germany).

\section{Statistical Analysis}

The statistical analysis consisted of either an ANOVA followed by the appropriate post hoc test or Student's t test. The statistical analyses were performed with Prism GraphPad for Windows (Prism 5, GraphPad Software, San Diego, Calif., USA). A value of $\mathrm{p}<0.05$ was considered significant. The results are presented as the means \pm SD.

\section{Results}

\section{LL-37 Selectively Enhances the Expression and Membrane Distribution of Various TJ Proteins in Human Keratinocytes}

To investigate the effects of LL-37 on the skin TJ barrier function, we first analyzed whether LL-37 could induce the expression of TJ proteins in normal human keratinocytes. As shown in figure 1a, following LL-37 stimulation for 24 $\mathrm{h}$, the mRNA expression levels of claudin-1, 3-7, 9, 12, 14, 16,17 and occludin significantly increased in a dose-dependent manner. However, LL-37 did not significantly af-

Fig. 1. LL-37 increases TJ component expression at the mRNA and protein levels in keratinocytes. a Human keratinocytes were incubated with $5-20 \mu \mathrm{g} / \mathrm{ml}$ of LL-37 or medium alone for $24 \mathrm{~h}$. Following the incubation, total RNA was extracted and reverse transcribed into cDNA, and real-time PCR was performed. The values from five separate experiments represent fold increases in gene expression relative to the values of controls stimulated with medium alone (Med). ${ }^{*} \mathrm{p}<0.05$; $^{* *} \mathrm{p}<0.01$; $^{* * *} \mathrm{p}<0.001$. The numbers on Med bars represent the threshold cycle, Ct, values of mRNAs from non-stimulated cells. b Human keratinocytes were stimulated with 10 and $20 \mu \mathrm{g} / \mathrm{ml}$ of LL-37 or the diluent alone (Med: plain white bars, $10 \mu \mathrm{g} / \mathrm{ml}$ : dotted bars, $20 \mu \mathrm{g} / \mathrm{ml}$ : striped bars) for 48-96 h. The levels of TJ proteins in cell lysates were determined by Western blotting. The results of one representative experiment of four separate experiments yielding similar results are shown. For the bar graphs, bands were quantified by densitometry to correct for protein loading discrepancies. The data represent the ratio of the intensity of the target protein divided by that of $\beta$-actin. CLDN = Claudin; OCLN = occludin.

LL-37 Increases Human Epidermal Barrier Function fect the mRNA expression levels of other TJ proteins, such as JAM-1 3 and zonula occludens 1 3 (data not shown). Because LL-37 increased the gene expression levels of various $\mathrm{TJ}$ components, we examined whether this HDP could also elevate the protein levels of TJ proteins. As determined by a Western blot analysis, LL-37 selectively increased the total protein expression of claudin-1, 3, 4, 7, 9, 14 and occludin. The increases in protein expression occurred at 48 $\mathrm{h}$, and most of them had become more remarkable at 72 and $96 \mathrm{~h}$ (fig. 1b). Interestingly, LL-37 had no effect on the protein expression of claudin-5, 6, 12, 16 or 17 (data not shown), suggesting that LL-37 selectively regulates TJ components in keratinocytes.

The membrane distribution of TJ proteins is essential for the formation of the TJ barrier; increases in the total amounts of TJ proteins do not necessarily prove the functionality of these proteins. Therefore, the effect of LL-37 on the membrane distribution of TJ proteins was examined. As seen in figure 2, among the TJ proteins for which total protein levels were increased by LL-37, claudin-1, 3 , 4, 7 and occludin were widely distributed at the cell-cell borders upon LL-37 stimulation, suggesting that these TJ proteins function to form the TJ barrier. In contrast, no membrane distribution of claudin- 9 or 14 was observed. The whole blots of claudin- 9 and 14 are shown in online supplementary figure $\mathrm{S} 1$.

\section{LL-37 Increases the TER and Decreases the Paracellular Diffusion of FITC-Dextran through Keratinocyte Layers}

Because LL-37 induced changes in the membrane distribution of certain TJ proteins, we examined whether these changes were associated with the regulation of the TJ barrier function. First, we assessed the TER, a highly sensitive parameter of TJ ionic permeability [13], at different times. Compared with untreated keratinocyte layers, cells that were stimulated with 10 or $20 \mu \mathrm{g} / \mathrm{ml}$ of LL37 did not exhibit significant increases in TER values until $72 \mathrm{~h}$, after which time the TER values gradually increased, reaching maximal values at $96 \mathrm{~h}$. The TER then decreased to approximately $70 \%$ of the maximal values at $120 \mathrm{~h}$ (fig. 3a).

TJs restrict not only the paracellular permeability of ions (measured by TER) but also the permeability of larger solutes (paracellular flux). Therefore, we measured the paracellular permeability of a membrane-impermeant tracer, 4-kDa FITC-dextran, a marker of paracellular transport [18]. LL-37-stimulated keratinocyte layers were incubated for $2 \mathrm{~h}$ with 4 - $\mathrm{kDa}$ FITC-dextran, and the apical-to-basolateral diffusion was determined by measur- 
Fig. 2. LL-37 enhances membrane distribution of TJ proteins. Keratinocytes grown to confluence on collagen I-coated chamber slides were stimulated with $20 \mu \mathrm{g} / \mathrm{ml}$ of LL37 or diluent alone (Medium) for $96 \mathrm{~h}$. Following fixation in methanol, the cells were processed for overnight immunofluorescence staining with antibodies against claucontrols (mouse IgG1, rabbit IgG and goat $\operatorname{IgG}$ ), followed by incubation with specific secondary antibodies coupled to Alexa 594. TJ proteins were visualized in red using confocal laser scanning microscopy. The results of one representative experiment of three separate experiments yielding similar results are shown. Scale bar $=10 \mu \mathrm{m}$. din-1, 3, 4, 7, 9, 14 and occludin, or isotype

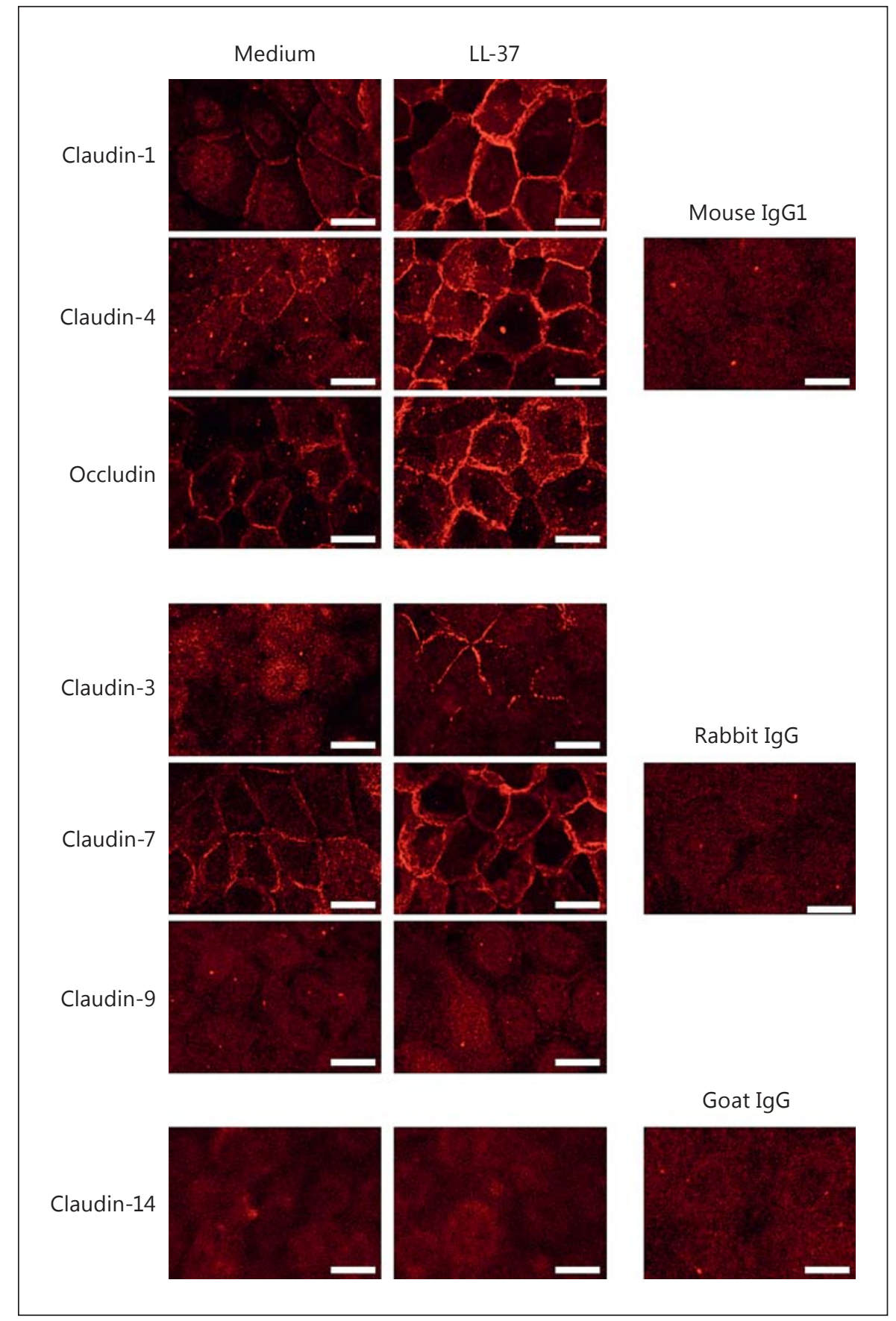

ing the fluorescence in the basolateral medium. Figure $3 \mathrm{~b}$ shows that compared with the control layers, which exhibited high levels of FITC-dextran flux, the LL-37 -treated keratinocyte layers had significantly decreased FITC-dextran flux from the apical compartment to the basolateral compartment $24 \mathrm{~h}$ after stimulation. The permeability underwent a further, gradual decrease to a minimum level at $96 \mathrm{~h}$ before progressively increasing.

These observations suggest that LL-37 regulates TJ barrier function.

\section{LL-37-Induced Regulation of TJ Barrier Function in}

Keratinocyte Layers Is Inhibited by Ochratoxin A

To confirm that the LL-37-induced improvement in the TJ barrier function was caused by the increased expression of claudins, we blocked the LL-37-mediated reg- 


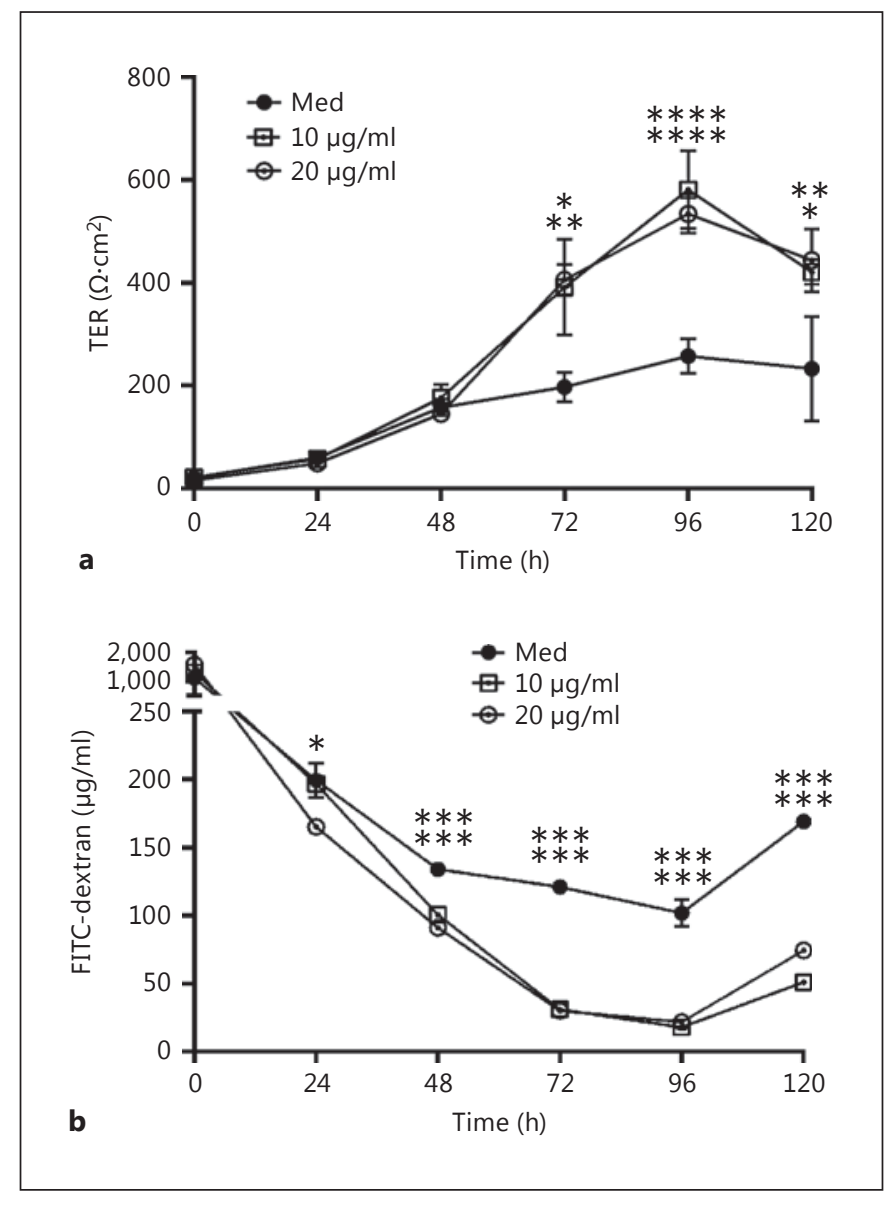

Fig. 3. LL-37 enhances TER and decreases paracellular flux in keratinocyte layers. Human keratinocyte layers grown on transwell inserts were stimulated with 10 or $20 \mu \mathrm{g} / \mathrm{ml}$ of LL-37 for $0-120 \mathrm{~h}$, and the TER (a) and paracellular flux (b) of 4-kDa FITC-dextran were determined as described in Materials and Methods. The values obtained from five separate experiments using stimulated and non-stimulated cells (Med) were compared. ${ }^{*} \mathrm{p}<0.05$; ${ }^{* *} \mathrm{p}<0.01$; *** $\mathrm{p}<0.001 ;{ }^{* * * *} \mathrm{p}<0.0001$.

ulation of TER and paracellular flux using ochratoxin A, a toxin that affects TJ barrier properties by removing specific claudin isoforms from the TJ network [18]. As shown in figure $4 \mathrm{a}$, pretreatment of keratinocyte layers with 10 and $100 \mathrm{nM}$ of ochratoxin A for $24 \mathrm{~h}$ significantly reduced the TER to the baseline values in LL-37-stimulated cells. Furthermore, ochratoxin A also altered the LL-37-induced decrease in the paracellular flux of $4-\mathrm{kDa}$ FITCdextran. The addition of ochratoxin A to the LL-37-stimulated layers increased the diffusion of 4-kDa FITC-dextran in a dose-dependent manner, causing a maximum increase in the paracellular flux of approximately three-

LL-37 Increases Human Epidermal Barrier Function fold. The concentrations of ochratoxin A used in this study did not significantly affect the basal TER or paracellular flux in non-stimulated cells.

We confirmed that the weakening of the TJ barrier function by ochratoxin A was due to the ability of this toxin to inhibit claudin expression. As seen in figure $4 \mathrm{~b}$, ochratoxin A reduced the total protein expression of claudin-1, 3, 4, 9, 14 and occludin, but it had no effect on claudin-7. This result implies that the LL-37-mediated regulation of TJ barrier function was under the control of ochratoxin $\mathrm{A}$.

\section{LL-37 Regulates TJ Barrier Function through the Activation of aPKC $\zeta / \lambda$}

To examine the mechanism by which LL-37 regulates TJ barrier function, we first investigated the involvement of aPKCs, which are considered potential regulators of TJ assembly. Specifically, the $\mathrm{aPKC} \mathrm{t} / \lambda$ and $\mathrm{aPKC} \zeta$ isoforms are associated with TJ proteins [19]. Using Western blots, we first assessed whether LL-37 induces the phosphorylation of aPKCs. As shown in figure 5a, LL-37 increased the amount of aPKC $\zeta / \lambda$ phosphorylation at $2 \mathrm{~h}$. This increase was more remarkable from $4 \mathrm{~h}$ until $72 \mathrm{~h}$ and had faded slightly at $96 \mathrm{~h}$.

Because the pan-PKC inhibitor GF109203X has been reported to hamper the TJ barrier function [19], we investigated the requirement for aPKC activation in LL-37-mediated TJ barrier function by pretreating keratinocyte layers with GF109203X. As shown in figure 5b, GF109203X disrupted the improved TJ barrier produced by the LL37-stimulated keratinocyte layers by decreasing the TER and increasing the paracellular flux of 4-kDa FITC-dextran to the basal levels, and it had no effect on the TJ barrier function in non-stimulated cells. This result implies that LL-37 regulates TJ barrier function through the aPKC signaling pathway.

\section{Activation of Rac1 Is Necessary for LL-37-Mediated Regulation of TJ Barrier Function in Keratinocyte Layers}

Racl activation is required for TJ formation and the maturation of epidermal keratinocytes, and this activation is associated with the activation of aPKC $\zeta$ [19]. Therefore, we hypothesized that LL-37 regulates TJ barrier function through the activation of Racl. Following the stimulation of keratinocytes with LL-37, changes in Racl activation levels were evaluated using a Rac1 activation pull-down assay. As shown in figure 6a, upon LL-37 stimulation, the activation of Rac1 (GTP-bound Rac1) was rapid and transient at $5 \mathrm{~min}$, and it was no longer ob- 
Fig. 4. Effects of ochratoxin A on LL37-mediated regulation of keratinocyte layer permeability and expression of $\mathrm{TJ}$ proteins. a Keratinocyte layers were pretreated with 10 and $100 \mathrm{nM}$ of ochratoxin $\mathrm{A}$ (OTA) or $0.1 \%$ DMSO for $24 \mathrm{~h}$ and were then stimulated with $20 \mu \mathrm{g} / \mathrm{ml}$ of LL-37 or diluent alone (Med) for $96 \mathrm{~h}$. The TER and paracellular flux of 4 -kDa FITC-dextran were measured. The values obtained from four separate experiments were compared between stimulated cells (LL-37) and the presence and absence of inhibitor (Med, OTA). ${ }^{*} \mathrm{p}<0.05 ;{ }^{* *} \mathrm{p}<0.01{ }^{* * *} \mathrm{p}<0.001$. b Keratinocytes were pretreated with 100 nM of OTA or $0.1 \%$ DMSO for $24 \mathrm{~h}$ and were then stimulated with $20 \mu \mathrm{g} / \mathrm{ml}$ of LL37 or the diluent alone (Med) for $48 \mathrm{~h}$. The levels of TJ proteins in cell lysates were determined by Western blotting. The results of one representative experiment of three separate experiments yielding similar results are shown. For the bar graphs, bands were quantified by densitometry to correct for protein loading discrepancies. The data represent the ratio of the intensity of the target protein divided by that of $\beta$-actin. CLDN = Claudin; OCLN = occludin.
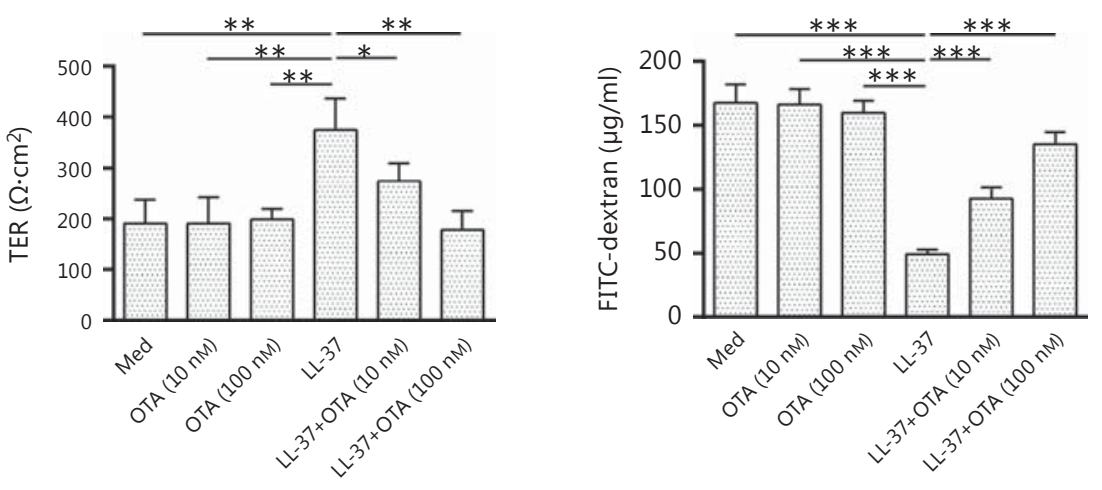

a
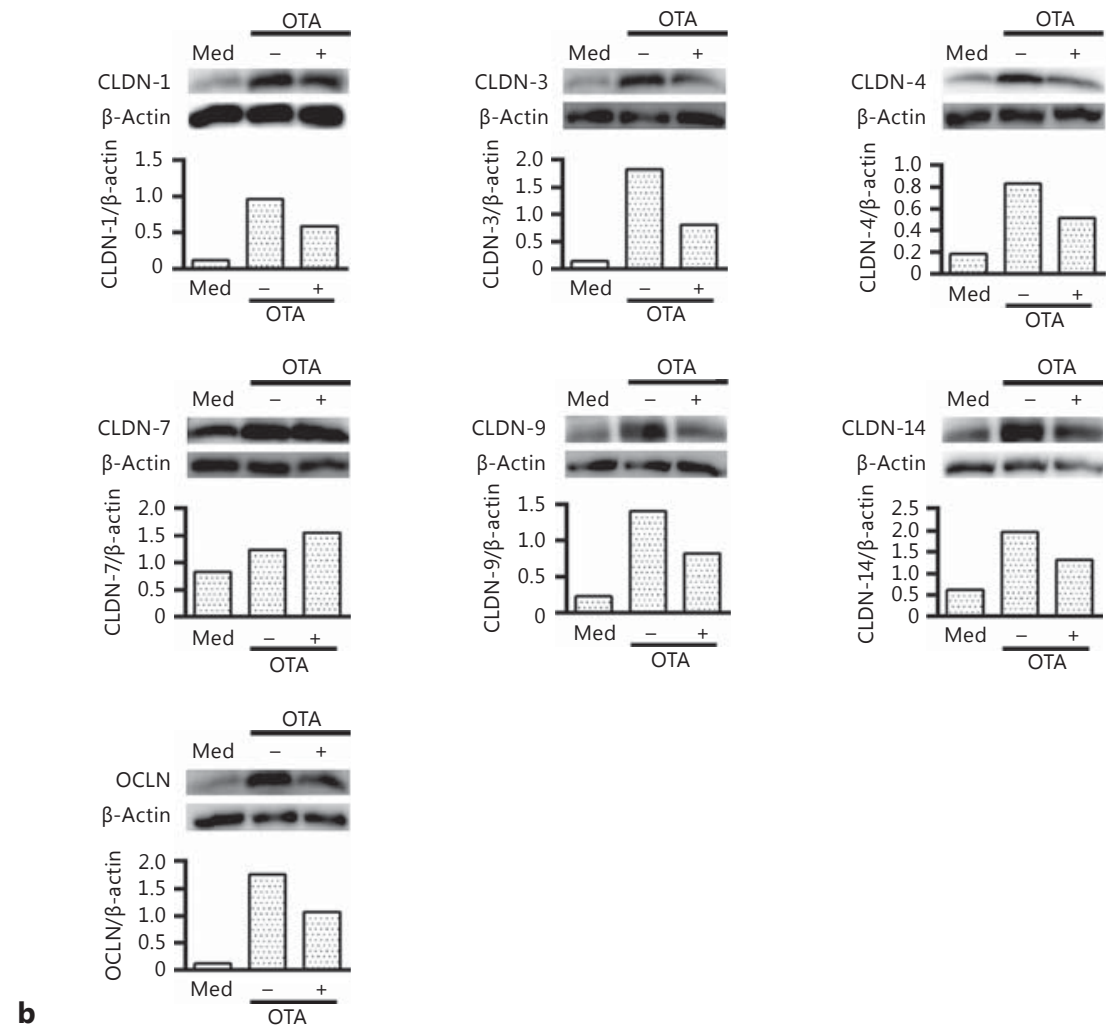

served from 15 min until $96 \mathrm{~h}$. The activation of Rac1 was necessary for the LL-37-mediated regulation of TJ barrier function because the pretreatment of keratinocyte layers with the Rac1-specific inhibitor NSC23766, which is known to block TER increases [20], attenuated the LL37 -induced increases in the TER values to the basal levels and enhanced the paracellular flux of 4-kDa FITC-dextran by approximately threefold in LL-37-stimulated cells (fig. 6b). This result indicates that Rac1 activation is re- quired for the LL-37-induced improvement in TJ barrier function.

\section{LL-37 Activates GSK-3 $\alpha / \beta$, Which Is Necessary for the Regulation of TJ Barrier Function}

GSK-3, which comprises the GSK- $3 \alpha$ and GSK- $3 \beta$ isoforms, has been implicated in the maintenance of epithelial barrier function by selectively regulating TJ protein expression $[21,22]$. An increase in the phosphorylation 


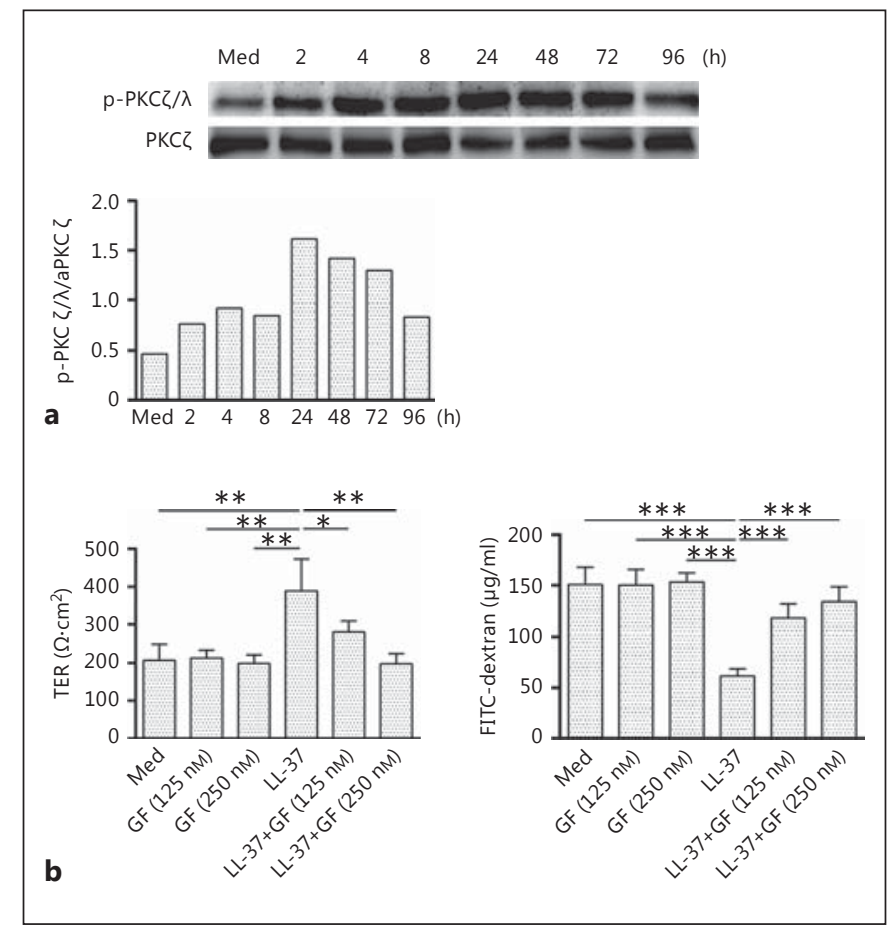

Fig. 5. LL-37 regulates TJ barrier function through activation of aPKC $\zeta / \lambda$. a Human keratinocytes were incubated with $20 \mu \mathrm{g} / \mathrm{ml}$ of LL-37 or diluent alone (Med) for 2-96 h and lysed. Equal amounts of proteins were immunoblotted using antibodies directed against the phosphorylated PKC $\zeta / \lambda(\mathrm{p}-\mathrm{PKC} \zeta / \lambda)$ and $\mathrm{PKC} \zeta$ proteins. The results of one representative experiment of four separate experiments yielding similar results are shown. For the bar graph, bands were quantified by densitometry to correct for protein loading discrepancies. The data represent the ratio of the intensity of $\mathrm{p}-\mathrm{PKC} \zeta / \lambda$ divided by that of PKC $\zeta$ protein. $\mathbf{b}$ Keratinocyte layers were pretreated with 125 and $250 \mathrm{nM}$ of GF109203X or $0.1 \%$ DMSO for $48 \mathrm{~h}$ and were then stimulated with $20 \mu \mathrm{g} / \mathrm{ml}$ of LL-37 or diluent alone (Med) for $96 \mathrm{~h}$. The TER and paracellular flux were then determined. The values obtained from four separate experiments were compared between stimulated cells (LL-37) and the presence and absence of inhibitor (Med, GF). ${ }^{*} \mathrm{p}<0.05$; ${ }^{* *} \mathrm{p}<$ $0.01{ }^{* * *} \mathrm{p}<0.001$.

of GSK-3 $\alpha / \beta$ at Tyr279/Tyr216 has been correlated with GSK-3 activation by various stimuli [21]. Hence, we investigated the effects of LL-37 on GSK-3 phosphorylation and the involvement of this kinase in the LL-37-mediated regulation of TJ barrier function. A Western blot analysis using an antibody that recognizes the tyrosine-phosphorylated version of both the GSK-3 $\alpha$ and GSK-3 $\beta$ isoforms revealed that LL-37 considerably enhanced the phosphorylation of GSK-3 $\alpha / \beta$ at Tyr279/Tyr216 at $2 \mathrm{~h}$, and this phosphorylation was sustained for $96 \mathrm{~h}$. No differences were detected in the total amount of GSK-3 $\alpha / \beta$ (fig. 7a). In contrast, LL-37 did not alter the phosphorylation of GSK-3 $\alpha / \beta$ at Ser21/Ser9 (data not shown), a phosphorylation that is known to inactivate GSK-3 [21], suggesting that LL-37 induces GSK-3 activation in keratinocytes. This activation was required for the LL-37-mediated regulation of $\mathrm{TJ}$ barrier function: the treatment of keratinocyte layers with SB 415286, which inhibits GSK-3 by reducing the TER and increasing paracellular permeability [22], resulted in a dramatic decrease in the TER to the baseline level while markedly increasing the paracellular flux of $4 \mathrm{kDa}$-FITC-dextran (fig. 7b).

\section{Activation of PI3K Is Required for LL-37-Induced \\ Regulation of TJ Barrier Function}

PI3K has been shown to be involved in the assembly and regulation of the epithelial barrier, and the PI3K pathway has been implicated in GSK-3 phosphorylation [19]. Therefore, we postulated that PI3K might be involved in the LL-37-induced regulation of TJ barrier function. In support of our hypothesis, Western blot results revealed an increase in PI3K (p85/p55) following a $4 \mathrm{~h}$ stimulation with LL-37; this PI3K activation was sustained for $96 \mathrm{~h}$ (fig. 8a). Next, we confirmed the requirement for PI3K activation in LL-37-regulated TJ barrier function by pretreating keratinocyte layers with a PI3Kspecific inhibitor, wortmannin. As shown in figure $8 \mathrm{~b}$, wortmannin completely abolished the increases in TER values to the baseline level in LL-37-stimulated layers, and it dose-dependently increased the paracellular diffusion of 4-kDa FITC-dextran by up to threefold. This finding indicates that LL-37 improved the epidermal permeability barrier function via the PI3K signaling pathway.

\section{LL-37 Increases the Expression of Keratinocyte \\ Differentiation Markers}

In addition to forming a selective paracellular barrier, TJs play a crucial role in keratinocyte differentiation: the formation of functional TJs in the epidermis is a prerequisite for normal differentiation, and the impairment of keratinocyte terminal differentiation can influence TJ protein expression [23]. Therefore, we hypothesized that LL-37 might also influence the expression of differentiation markers. Among the investigated differentiation markers, LL-37 considerably induced the protein expression of filaggrin, involucrin, keratin 1, keratin 10 and transglutaminase 1 (fig. 9a). Because there was no remarkable change in the high-molecular filaggrin, it seems that LL-37 is unlikely involved in the processing of filaggrin (online suppl. fig. S2). There were no significant effects of LL-37 on the expression of loricrin or transgluta- 
Fig. 6. LL-37 enhances TJ barrier function via GTP-Rac1 activation. a Keratinocytes were incubated with $20 \mu \mathrm{g} / \mathrm{ml}$ of LL-37 or diluent alone (Med) for 1-15 min (left) or for $5 \mathrm{~min}$ to $96 \mathrm{~h}$ (right) and were then lysed. The GTP-bound Rac1 (GTP-Rac1) was quantified using a Racl activation assay kit. The results of one representative experiment of three separate experiments yielding similar results are shown. For the bar graphs, bands were quantified by densitometry to correct for protein loading discrepancies. The data represent the ratio of the intensity of GTP-Racl divided by that of total Rac1. b Keratinocyte layers grown on transwell inserts were pretreated with 50 and $100 \mu \mathrm{M}$ of NSC23766 or $0.1 \%$ DMSO for $24 \mathrm{~h}$ and were then stimulated with $20 \mu \mathrm{g} / \mathrm{ml}$ of LL-37 or diluent alone (Med) for $96 \mathrm{~h}$. The TER and paracellular flux were then determined. The values obtained from four separate experiments were compared between stimulated cells (LL-37) and the presence and absence of inhibitor (Med, NSC). ${ }^{*} \mathrm{p}<0.05$; ${ }^{* *} \mathrm{p}<$ $0.01{ }^{* * *} \mathrm{p}<0.001$.

Fig. 7. LL-37 increases TJ barrier function through GSK- $3 \alpha / \beta$ activation. a Keratinocytes were incubated with $20 \mu \mathrm{g} / \mathrm{ml}$ LL-37 or diluent alone (Med) for 2-96 h, and lysates were separated by SDS-PAGE using antibodies directed against phosphorylated (p-)GSK-3 $\alpha / \beta$ (Tyr279/Tyr216) and GSK$3 \alpha / \beta$ proteins. The results of one representative experiment of three separate experiments yielding similar results are shown. For the bar graph, both upper and lower bands were quantified by densitometry to correct for protein loading discrepancies. The data represent the ratio of the intensity of $\mathrm{p}-\mathrm{GSK}-3 \alpha / \beta$ divided by that of total GSK-3 $\alpha / \beta$ protein. b Keratinocyte layers grown on transwell inserts were pretreated with 25 and $50 \mathrm{nM}$ of SB 415286 or $0.1 \%$ DMSO for $48 \mathrm{~h}$ and were then stimulated with $20 \mu \mathrm{g} / \mathrm{ml}$ of LL-37 or diluent alone (Med) for $96 \mathrm{~h}$. The TER and paracellular flux were determined. The values obtained from four separate experiments were compared between stimulated cells (LL-37) and the presence and absence of inhibitor (Med, SB). ${ }^{*} \mathrm{p}<0.05 ;{ }^{* *} \mathrm{p}<0.01{ }^{* * *} \mathrm{p}<$ 0.001 .
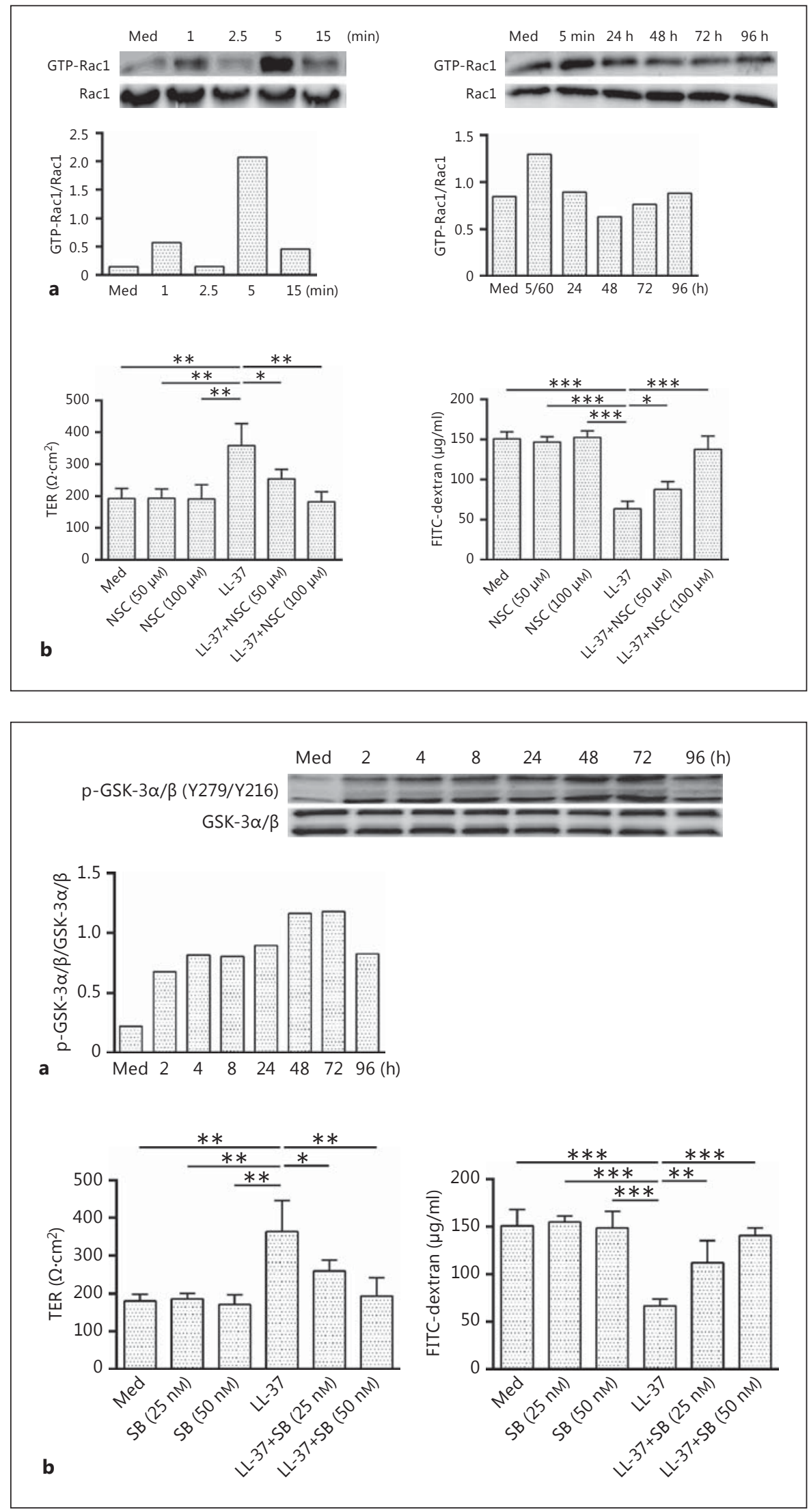
Fig. 8. LL-37 regulates TJ barrier function through PI3K activation. a Keratinocytes were incubated with $20 \mu \mathrm{g} / \mathrm{ml}$ of LL-37 or diluent alone (Med) for 2-96 h and lysed. Equal amounts of protein were immunoblotted using antibodies directed against the phosphorylated (p-)PI3K (p85/p55) and PI3K (p85) proteins. The results of one representative experiment of three separate experiments yielding similar results are shown. For the bar graph, both upper and lower bands were quantified by densitometry to correct for protein loading discrepancies. The data represent the ratio of the intensity of $\mathrm{p}$-PI3K (p85/p55) divided by that of PI3K (p85) protein. b Keratinocyte layers were pretreated with 1 and $10 \mu \mathrm{M}$ of wortmannin (Wort) or $0.1 \%$ DMSO for 48 $\mathrm{h}$ and were then stimulated with $20 \mu \mathrm{g} / \mathrm{ml}$ of LL-37 or diluent alone (Med) for $96 \mathrm{~h}$. The TER and paracellular flux were determined. The values obtained from four separate experiments were compared between stimulated cells (LL-37) and the presence and absence of inhibitor (Med, Wort). ${ }^{*} \mathrm{p}<0.05 ;{ }^{* *} \mathrm{p}<0.01$; $^{* *} \mathrm{p}<0.001$.
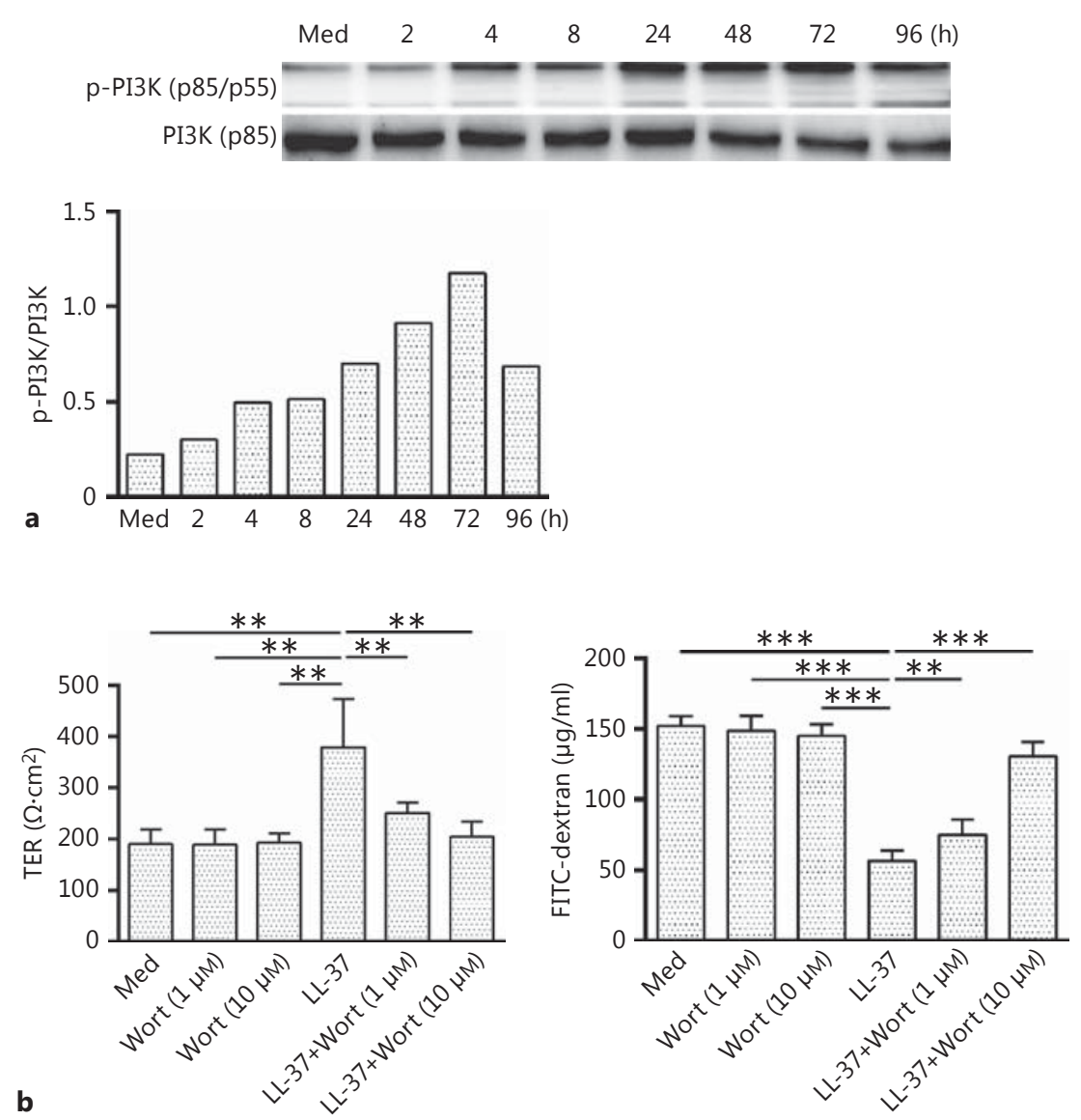

minase 3 (data not shown). To evaluate the relationship between LL-37-mediated TJ regulation and keratinocyte differentiation, we examined the effects of ochratoxin A on the expression of keratinocyte differentiation makers. As shown in figure 9b, ochratoxin A suppressed the expression of filaggrin, involucrin, keratin 1 , keratin 10 and transglutaminase 1 , suggesting an association between the LL-37-mediated regulation of TJ barrier function and keratinocyte differentiation.

\section{Discussion}

In this study, we have shown that, in addition to its antimicrobial and other immunomodulatory functions, LL37 has the ability to upregulate the expression and membrane distribution of TJ components and to improve the TJ barrier function in human keratinocytes, as demonstrated by an increased TER and a reduced paracellular flux through keratinocyte layers. This improvement in TJ barrier function was controlled by, at a minimum, the activation of the aPKC, Rac1, GSK-3 and PI3K pathways.

Although the role of the stratum corneum in the skin permeability barrier has been widely reported, the TJ-associated barrier was largely ignored until the discovery that mice deficient in the TJ component claudin-1 exhibited postnatal lethality due to the absence of an epidermal diffusion barrier [24]. Recently, De Benedetto et al. [8] proposed that the defective expression of claudin-1 and claudin-23 may contribute to the barrier dysfunction in uninvolved $\mathrm{AD}$ skin compared with uninvolved psoriatic skin, in which TJ protein levels are normal, increased or downregulated [14-16]. LL-37 is overexpressed in lesional psoriasis but downregulated in lesional $\mathrm{AD}$ [6]. Therefore, we speculated that this differential expression may play a key role in regulating the $\mathrm{TJ}$ barrier function. LL-37 selectively increased the mRNA and protein levels of numerous TJ proteins, including claudin-1, 3, 4, 7 and occludin. The 
Fig. 9. LL-37 increases the expression of keratinocyte differentiation markers under the control of ochratoxin A. a Keratinocytes were stimulated with 10 and $20 \mu \mathrm{g} / \mathrm{ml}$ of LL-37 or the diluent alone (Med) for $48 \mathrm{~h}$. Cell lysates were then obtained, and equal amounts of total protein were subjected to $12.5 \%$ SDS-PAGE analysis. The blots were incubated with antibodies against filaggrin, involucrin, keratin 1, keratin 10 and transglutaminase 1 . The filaggrin bands correspond to the $40-\mathrm{kDa}$ monomer. The results of one representative experiment of four separate experiments yielding similar results are shown. For the bar graphs, bands were quantified by densitometry to correct for protein loading discrepancies. The data represent the ratio of the intensity of each marker divided by that of $\beta$-actin. b Keratinocytes were pretreated with $100 \mathrm{nM}$ of ochratoxin A (OTA) or $0.1 \%$ DMSO for $24 \mathrm{~h}$ and were then stimulated with $20 \mu \mathrm{g} / \mathrm{ml}$ of LL-37 or diluent alone (Med) for $48 \mathrm{~h}$. The levels of differentiation markers in cell lysates were determined by Western blotting. The results of one representative experiment of three separate experiments yielding similar results are shown. For the bar graphs, bands were quantified by densitometry to correct for protein loading discrepancies. The data represent the ratio of the intensity of each marker divided by that of $\beta$-actin.

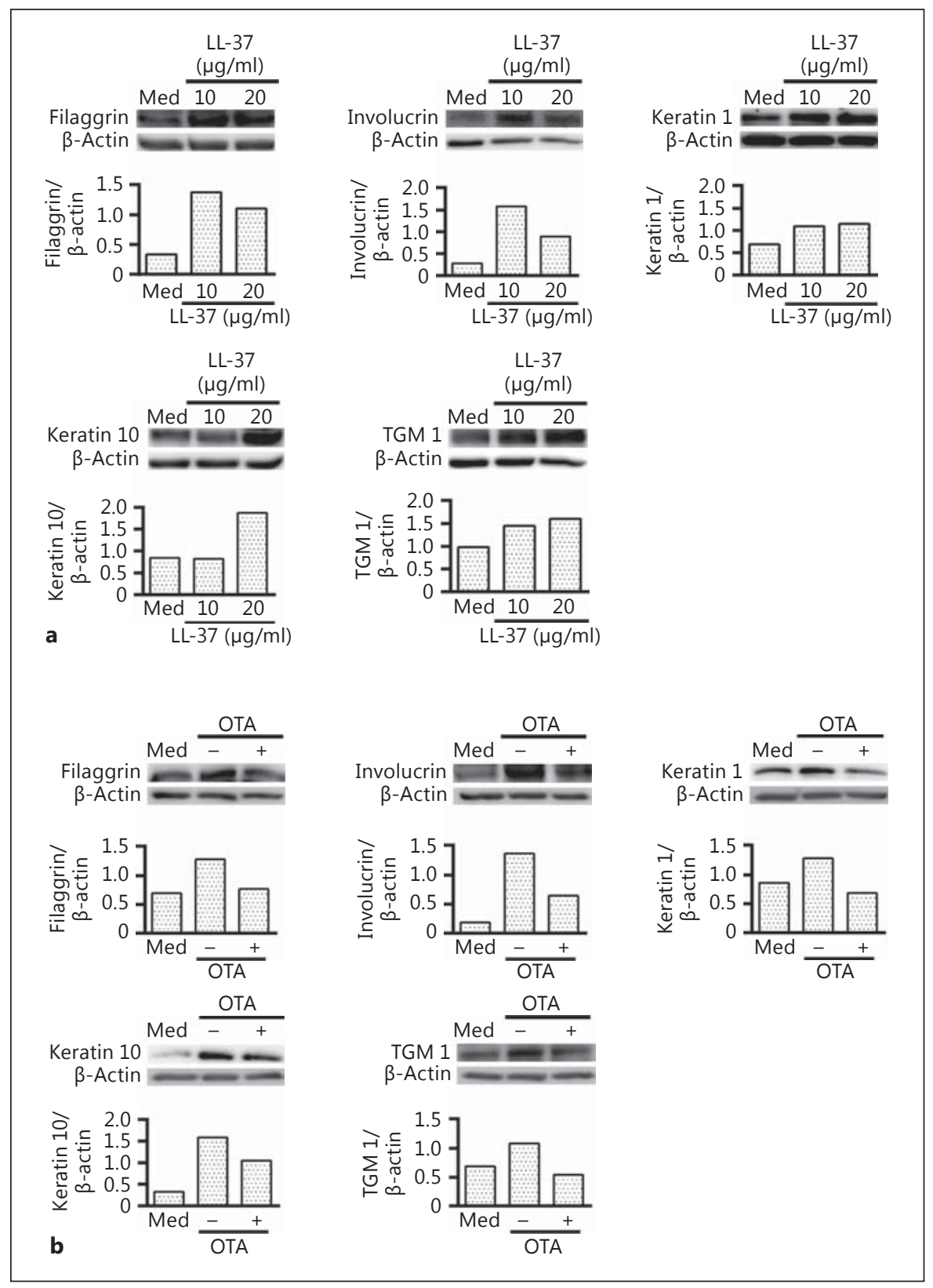

membrane distribution of these proteins was widely increased by LL-37 stimulation, suggesting their important role in LL-37-mediated TJ function. Ochratoxin A treatment weakened the above TJ proteins, except claudin-7, but it also suppressed the total protein expression of claudin-9 and claudin-14, which failed to localize to the membrane after LL-37 stimulation. It has been shown that the absence or presence of TJ proteins does not provide definitive evidence that these proteins are functional or dysfunctional [25]; therefore, further investigations are neces- sary to clarify the functionality of claudin-7, 9 and 14. LL37 increased the expression of TJ proteins that are generally known to tighten the TJ barrier by enhancing TER and reducing paracellular permeability $[12,26]$, and LL-37 had no effect on claudin-2, 6 or 10 (data not shown), which tend to disrupt TJ barrier function [27]. LL-37-mediated TJ expression was observed at $48 \mathrm{~h}$ and was maintained for $96 \mathrm{~h}$; these changes occurred in tandem with the paracellular flux of FITC-dextran. However, changes in the TER values were not observed until $72 \mathrm{~h}$, after which time 
they increased to maximal values at $96 \mathrm{~h}$. Both TER and paracellular flux are used as parameters to assess epidermal permeability. However, these parameters are not always coupled, as has been observed in several other contexts [28-32], and the mechanism of this uncoupling remains poorly understood. Liu et al. [32] have postulated that whereas TER is a static indicator of the epithelial barrier to small ions, paracellular flux is a time-dependent, dynamic measurement of the barrier to larger solutes.

Because TJ proteins have been shown to regulate epithelial differentiation [24], we investigated whether LL37 also affects differentiation markers. As expected, LL37 increased the expression of various markers, including the early markers keratin 1 and keratin 10 , the intermediate markers involucrin and transglutaminase 1 , and the late marker filaggrin. Ochratoxin weakened the LL-37-induced increases in the expression of differentiation markers, which suggests that there is an association between the LL-37-mediated regulation of TJ barrier function and keratinocyte differentiation. It has been shown that TJ proteins can influence differentiation. For instance, keratinocytes from claudin-1-deficient mice exhibited a downregulation of involucrin and altered filaggrin expression [33]. Turksen and Troy [34] demonstrated that the overexpression of claudin- 6 resulted in the aberrant expression of various differentiation markers, including keratin 1, involucrin, filaggrin, loricrin and transglutaminase 3. However, TJ proteins have also been shown to be influenced by differentiation. For example, the downregulation of $\mathrm{TJ}$ proteins has been reported in patients with filaggrin mutations [23]. Interestingly, newborn sodium channel $\alpha$-deficient mice showed impaired differentiation but exhibited normal TJs and TJ barrier function, which suggests that $\mathrm{TJ}$ proteins and keratinocyte differentiation may be independent of one another [23].

A large number of molecular components have been reported to be required for TJ formation [19]. Among these components, we focused on the aPKC, Rac1, GSK-3 and PI3K pathways to explore the molecular mechanisms by which LL-37 regulates TJ barrier function. We found that the above molecules were indispensable for the LL37-mediated regulation of TJ barrier function (fig. 5-8). Furthermore, our observation that specific inhibition of aPKC, Rac1, GSK-3 and PI3K resulted in a significant decrease of the LL-37-induced expression of claudin-1, 3, 4, 9,14 and occludin, but not claudin-7, suggests the importance of these TJ proteins in the LL-37-regulated TJ function (online suppl. fig. S3).

Previous studies have demonstrated that both the $\operatorname{aPKC} \zeta$ and $\mathrm{aPKC} \mathrm{\imath} / \lambda$ isoforms are expressed and acti- vated in the epidermis $[19,35]$, interact directly with TJs and regulate the formation of the $\mathrm{TJ}$ barrier through the activation of TJ proteins [36,37]. Furthermore, aPKC has been reported to restore $\mathrm{TJ}$ formation in keratinocytes in which TJ formation was defective, which further demonstrates the importance of this enzyme in TJ barrier formation and function [38]. Thus, our observation that LL-37 activates aPKC $\zeta / \lambda$ and that the inhibition of this enzyme disrupts LL-37-mediated TJ barrier function without significantly affecting TJ function in non-stimulated cells implies that LL-37 acts through an aPKC pathway to regulate epidermal permeability. Reports have shown that aPKC functions downstream of Racl, and the inhibition of GTP-Rac1 (the active form of Rac1) and aPKC suppresses TJ formation [38]. Furthermore, the deterioration of TJ functionality in the skin is accompanied by the downregulation of both GTP-Rac1 and aPKC [39]. Therefore, Rac1 involvement was also investigated. As expected, LL-37 increased Rac1 activation, and the Rac1 inhibitor NSC23766 reversed the LL-37-mediated increase in TER and decrease in paracellular flux. Upon stimulation, Rac1 proteins are generally activated very rapidly and transiently $[40,41]$. However, it is not clear whether the NSC23766 effect on the LL-37-mediated improvement in TJ function (measured at $96 \mathrm{~h}$ ) observed in the present study was direct or indirect - a rapid and transient Rac1 activation is also known to regulate other pathways that control TJ function. For example, the prolonged activation of Rho, which enhances TJ barrier function [42], is dependent on the prior activation of Rac1 [40]. Furthermore, PI3K, which can be activated by Rac1 [43], regulates TJ barrier function [the current study and 19]. Further studies on the effect of LL-37 on Rho activation are necessary to confirm our hypothesis.

Another molecular component implicated in the regulation of the TJ barrier is GSK-3, which comprises two isoforms, GSK-3 $\alpha$ and GSK-3 $\beta$ [21]. GSK-3 $\alpha$ and GSK-3 $\beta$ function in the regulation of the normal epithelial barrier function by selectively upregulating TJ proteins, such as claudins and occludin $[21,22]$. Until recently, GSK-3 was considered a constitutively active enzyme, the activity of which was decreased upon cell stimulation. The inactivation of GSK-3 occurs through the phosphorylation of GSK- $\alpha$ at Ser21 and GSK-3 $\beta$ at Ser9 [21]. However, a number of reports have recently indicated that an increase in the level of tyrosine phosphorylation (Tyr279 in GSK- $\alpha$ and Tyr216 in GSK-3 $\beta$ ) is correlated with GSK-3 activation in response to various stimuli, including lysophosphatidic acid, apoptotic stimuli, ischemia, a transient rise in intracellular $\mathrm{Ca}^{2+}$, and insulin [21]. Accord- 
ingly, we showed that LL-37 induced GSK-3 activation by increasing the tyrosine phosphorylation of both GSK- $\alpha$ and GSK- $\beta$ (Tyr279/Tyr216), but had no influence on GSK- $\alpha / \beta$ phosphorylation at Ser21/Ser9 (data not shown). Furthermore, because the pharmacological inhibition of GSK-3 suppressed the LL-37-induced regulation of TJ function, we confirmed that LL-37 regulates the TJ barrier via GSK-3 activation.

GSK-3 functions downstream of the PI3K pathway, which has also been implicated in the regulation of TJ proteins and their barrier function. Specifically, Little and coworkers [44] reported that PI3K signaling was required for the reorganization of TJ proteins and resistance to paracellular flux in porcine ileal epithelial cells following treatment with prostaglandins, as shown by the inhibitory effects of the PI3K inhibitors wortmannin and LY294002 [19]. PI3K also plays a direct role in strengthening the TJ barrier in response to glucocorticoids; this response is suppressed by $\mathrm{PI} 3 \mathrm{~K}$ inhibitors, and the tightening of the TJ barrier by glucocorticoids enhances the recruitment of the PI3K p85 subunit to TJs [19]. Accordingly, we demonstrated that LL-37 induced PI3K activation, which was parallel to the LL-37-induced changes in TER and paracellular flux, and the specific inhibition of PI3K reduced the improvement in the LL-37-mediated TJ barrier function, but not in the basal $\mathrm{TJ}$ barrier function. Thus, LL-37 may regulate TJ function through the activation of the PI3K signaling pathway. In some cases, the activation of the PI3K pathway can also affect TJ sealing, either by reducing TJ protein expression or inhibiting GSK-3 [19]. Therefore, no generalizations can be made regarding the physiological role of $\mathrm{PI} 3 \mathrm{~K}$ in the $\mathrm{TJ}$ barrier because distinct stimuli may result in opposite effects. Additional studies are necessary to determine the precise role of the PI3K pathway in TJ regulation.

In summary, the data presented here demonstrate that LL-37 selectively enhances the expression and membrane distribution of TJ proteins. Furthermore, this skin-derived HDP is involved in strengthening the TJ barrier function via, at a minimum, the activation of the aPKC, Rac1, GSK-3 and PI3K signaling pathways. Thus, in addition to its antimicrobial and immunomodulatory activities, we have described a previously unknown role for LL-37 as a contributor to cutaneous immunity by regulating the skin barrier function.

\section{Acknowledgements}

This work was supported in part by a Grant-in-Aid for Scientific Research from the Ministry of Education, Culture, Sports, Science and Technology of Japan, and by the Atopy (Allergy) Research Center, Juntendo University, Tokyo, Japan.

We would like to thank all of the members of the Atopy (Allergy) Research Center and the Department of Immunology of the Juntendo University Graduate School of Medicine for their comments and encouragement, Michiyo Matsumoto for secretarial assistance and Mutsuko Hara for technical assistance with the confocal microscope.

\section{References}

1 Niyonsaba F, Nagaoka I, Ogawa H, Okumura $\mathrm{K}$ : Multifunctional antimicrobial proteins and peptides: natural activators of immune systems. Curr Pharm Des 2009;15:23932413.

2 Zanetti M, Gennaro R, Romeo D: Cathelicidins: a novel protein family with a common proregion and a variable C-terminal antimicrobial domain. FEBS Lett 1995;374:1-5.

-3 Schauber J, Dorschner RA, Coda AB, Buchau AS, Liu PT, Kiken D, Helfrich YR, Kang S, Elalieh HZ, Steinmeyer A, Zugel U, Bikle DD, Modlin RL, Gallo RL: Injury enhances TLR2 function and antimicrobial peptide expression through a vitamin $\mathrm{D}$-dependent mechanism. J Clin Invest 2007;117:803-811.

-4 Nizet V, Ohtake T, Lauth X, Trowbridge J, Rudisill J, Dorschner RA, Pestonjamasp V, Piraino J, Huttner K, Gallo RL: Innate antimicrobial peptide protects the skin from invasive bacterial infection. Nature 2001;414:454457.
5 Henseler T, Christophers E: Disease concomitance in psoriasis. J Am Acad Dermatol 1995; 32:982-986.

-6 Ong PY, Ohtake T, Brandt C, Strickland I, Boguniewicz M, Ganz T, Gallo RL, Leung DY: Endogenous antimicrobial peptides and skin infections in atopic dermatitis. N Engl J Med 2002;347:1151-1160.

7 Harder J, Dressel S, Wittersheim M, Cordes J, Meyer-Hoffert U, Mrowietz U, Folster-Holst R, Proksch E, Schroder JM, Schwarz T, Glaser $\mathrm{R}$ : Enhanced expression and secretion of antimicrobial peptides in atopic dermatitis and after superficial skin injury. J Invest Dermatol 2010;130:1355-1364.

-8 De Benedetto A, Rafaels NM, McGirt LY, Ivanov AI, Georas SN, Cheadle C, Berger AE, Zhang K, Vidyasagar S, Yoshida T, Boguniewicz M, Hata T, Schneider LC, Hanifin JM, Gallo RL, Novak N, Weidinger S, Beaty TH, Leung DY, Barnes KC, Beck LA: Tight junction defects in patients with atopic dermatitis. J Allergy Clin Immunol 2011;127:773-786.e7.
9 Kirschner N, Rosenthal R, Furuse M, Moll I, Fromm M, Brandner JM: Contribution of tight junction proteins to ion, macromolecule, and water barrier in keratinocytes. J Invest Dermatol 2013;133:1161-1169.

10 Matter K, Aijaz S, Tsapara A, Balda MS: Mammalian tight junctions in the regulation of epithelial differentiation and proliferation. Curr Opin Cell Biol 2005; 17:453-458.

11 Niessen CM: Tight junctions/adherens junctions: basic structure and function. J Invest Dermatol 2007;127:2525-2532.

12 Anderson JM, Van Itallie CM: Physiology and function of the tight junction. Cold Spring Harb Perspect Biol 2009;1:a002584.

13 Van Itallie CM, Anderson JM: Claudins and epithelial paracellular transport. Annu Rev Physiol 2006;68:403-429. 
14 Itoh K, Kawasaki S, Kawamoto S, Seishima M, Chiba $\mathrm{H}$, Michibata $\mathrm{H}$, Wakimoto $\mathrm{K}$, Imai $\mathrm{Y}$, Minesaki Y, Otsuji M, Okubo K: Identification of differentially expressed genes in psoriasis using expression profiling approaches. Exp Dermatol 2005;14:667-674.

-15 Peltonen S, Riehokainen J, Pummi K, Peltonen J: Tight junction components occludin, ZO- 1 , and claudin- $1,-4$ and -5 in active and healing psoriasis. Br J Dermatol 2007;156: 466-472.

-16 Kirschner N, Poetzl C, von den Driesch P, Wladykowski E, Moll I, Behne MJ, Brandner JM: Alteration of tight junction proteins is an early event in psoriasis: putative involvement of proinflammatory cytokines. Am J Pathol 2009;175:1095-1106.

-17 Niyonsaba F, Ushio H, Nakano N, Ng W, Sayama K, Hashimoto K, Nagaoka I, Okumura K, Ogawa H: Antimicrobial peptides human beta-defensins stimulate epidermal keratinocyte migration, proliferation and production of proinflammatory cytokines and chemokines. J Invest Dermatol 2007;127: 594-604.

-18 Yuki T, Haratake A, Koishikawa H, Morita K, Miyachi Y, Inoue S: Tight junction proteins in keratinocytes: localization and contribution to barrier function. Exp Dermatol 2007;16: 324-330.

-19 Gonzalez-Mariscal L, Tapia R, Chamorro D: Crosstalk of tight junction components with signaling pathways. Biochim Biophys Acta 2008;1778:729-756.

-20 Baumer Y, Spindler V, Werthmann RC, Bunemann $M$, Waschke J: Role of Rac 1 and cAMP in endothelial barrier stabilization and thrombin-induced barrier breakdown. J Cell Physiol 2009;220:716-726.

21 Doble BW, Woodgett JR: Gsk-3: tricks of the trade for a multi-tasking kinase. J Cell Sci 2003;116:1175-1186.

-22 Severson EA, Kwon M, Hilgarth RS, Parkos CA, Nusrat A: Glycogen synthase kinase 3 (GSK-3) influences epithelial barrier function by regulating occludin, claudin-1 and E-cadherin expression. Biochem Biophys Res Commun 2010;397:592-597.

23 Kirschner N, Rosenthal R, Gunzel D, Moll I, Brandner JM: Tight junctions and differentiation - a chicken or the egg question? Exp Dermatol 2012;21:171-175.
Furuse M, Hata M, Furuse K, Yoshida Y, Haratake A, Sugitani Y, Noda T, Kubo A, Tsukita $\mathrm{S}$ : Claudin-based tight junctions are crucial for the mammalian epidermal barrier: a lesson from claudin-1-deficient mice. J Cell Biol 2002;156:1099-1111.

25 Kirschner N, Houdek P, Fromm M, Moll I, Brandner JM: Tight junctions form a barrier in human epidermis. Eur J Cell Biol 2010;89: 839-842.

26 Milatz S, Krug SM, Rosenthal R, Gunzel D, Muller D, Schulzke JD, Amasheh S, Fromm M: Claudin- 3 acts as a sealing component of the tight junction for ions of either charge and uncharged solutes. Biochim Biophys Acta 2010;1798:2048-2057.

27 Van Itallie CM, Fanning AS, Anderson JM: Reversal of charge selectivity in cation or anion-selective epithelial lines by expression of different claudins. Am J Physiol Renal Physiol 2003;285:F1078-F1084.

28 Balda MS, Whitney JA, Flores C, Gonzalez S, Cereijido M, Matter K: Functional dissociation of paracellular permeability and transepithelial electrical resistance and disruption of the apical-basolateral intramembrane diffusion barrier by expression of a mutant tight junction membrane protein. J Cell Biol 1996; 134:1031-1049.

29 Van Itallie CM, Fanning AS, Bridges A, Anderson JM: Zo-1 stabilizes the tight junction solute barrier through coupling to the perijunctional cytoskeleton. Mol Biol Cell 2009; 20:3930-3940.

30 Van Itallie CM, Fanning AS, Holmes J, Anderson JM: Occludin is required for cytokineinduced regulation of tight junction barriers. J Cell Sci 2010;123:2844-2852.

- 31 Fanning AS, Van Itallie CM, Anderson JM: Zonula occludens- 1 and -2 regulate apical cell structure and the zonula adherens cytoskeleton in polarized epithelia. Mol Biol Cell 2012; 23:577-590.

32 Liu KC, Jacobs DT, Dunn BD, Fanning AS, Cheney RE: Myosin-X functions in polarized epithelial cells. Mol Biol Cell 2012;23:16751687.

-33 Kirschner N, Haftek M, Niessen CM, Behne MJ, Furuse M, Moll I, Brandner JM: CD44 regulates tight-junction assembly and barrier function. J Invest Dermatol 2011;131:932943.

34 Turksen K, Troy TC: Permeability barrier dysfunction in transgenic mice overexpressing claudin 6. Development 2002;129:17751784 .
5 Helfrich I, Schmitz A, Zigrino P, Michels C, Haase I, le Bivic A, Leitges M, Niessen CM: Role of aPKC isoforms and their binding partners Par3 and Par6 in epidermal barrier formation. J Invest Dermatol 2007;127:782791.

36 Nunbhakdi-Craig V, Machleidt T, Ogris E, Bellotto D, White CL 3rd, Sontag E: Protein phosphatase $2 \mathrm{a}$ associates with and regulates atypical PKC and the epithelial tight junction complex. J Cell Biol 2002;158:967-978.

37 Stuart RO, Nigam SK: Regulated assembly of tight junctions by protein kinase C. Proc Natl Acad Sci USA 1995;92:6072-6076.

38 Mertens AE, Rygiel TP, Olivo C, van der Kammen R, Collard JG: The RAC activator Tiam1 controls tight junction biogenesis in keratinocytes through binding to and activation of the par polarity complex. J Cell Biol 2005;170:1029-1037.

- 39 Yuki T, Hachiya A, Kusaka A, Sriwiriyanont P, Visscher MO, Morita K, Muto M, Miyachi Y, Sugiyama Y, Inoue S: Characterization of tight junctions and their disruption by UVB in human epidermis and cultured keratinocytes. J Invest Dermatol 2011;131:744-752.

40 Nijhara R, van Hennik PB, Gignac ML, Kruhlak MJ, Hordijk PL, Delon J, Shaw S: Rac1 mediates collapse of microvilli on chemokine-activated T lymphocytes. J Immunol 2004;173:4985-4993.

41 Weston C, Gordon C, Teressa G, Hod E, Ren $\mathrm{XD}$, Prives J: Cooperative regulation by Rac and Rho of agrin-induced acetylcholine receptor clustering in muscle cells. J Biol Chem 2003;278:6450-6455.

-42 Persidsky Y, Heilman D, Haorah J, Zelivyanskaya M, Persidsky R, Weber GA, Shimokawa H, Kaibuchi K, Ikezu T: Rho-mediated regulation of tight junctions during monocyte migration across the blood-brain barrier in HIV-1 encephalitis (HIVE). Blood 2006; 107: 4770-4780.

43 Bokoch GM, Vlahos CJ, Wang Y, Knaus UG, Traynor-Kaplan AE: Rac GTPase interacts specifically with phosphatidylinositol 3-kinase. Biochem J 1996;315(pt 3):775-779.

44 Little D, Dean RA, Young KM, McKane SA, Martin LD, Jones SL, Blikslager AT: PI3K signaling is required for prostaglandin-induced mucosal recovery in ischemia-injured porcine ileum. Am J Physiol Gastrointest Liver Physiol 2003;284:G46-G56. 